
\title{
$\begin{array}{ll}\text { Research Square } & \begin{array}{l}\text { Preprints are preliminary reports that have not undergone peer review. } \\ \text { They should not be considered conclusive, used to inform clinical practice, } \\ \text { or referenced by the media as validated information. }\end{array}\end{array}$
}

\section{Self-care Practice and Associated Factors Among Hypertensive Follow Up Patients at East Gojam Zone Public Hospitals, North West Ethiopia, 2021}

Haymanot Mitiku Zeleke ( $\sim$ haymanotzeleke89@gmail.com )

Debre Markos University College of Health Science https://orcid.org/0000-0003-3539-0283

Birtuka Assefa

Debre Markos University

\section{Teshager Sergo}

Amanual health center

Nakachew Mekonnen

Debre Markos University

\section{Research}

Keywords: Hypertension, Self-care practice, Blood Pressure, Ethiopia

Posted Date: March 16th, 2021

DOI: https://doi.org/10.21203/rs.3.rs-303339/v1

License: @ (i) This work is licensed under a Creative Commons Attribution 4.0 International License. Read Full License 


\section{Abstract}

Background: Self-care practice is crucial for the prevention and management of Hypertension. Poorly controlled hypertension leads to cardiovascular complication as well as organ damage. Despite the availability of several effective pharmacologic and non-pharmacologic therapies, hypertension control remains suboptimal. Self-care practices allow hypertensive patients to have improved quality of life by avoiding complication and decrease health care expenditure.

Objective: we assessed self-care practice and its associated factors among Hypertensive Follow up patients at East Gojjam Zone public hospitals, Northwest Ethiopia, 2020.

Methods: Institution based cross sectional study was conducted by both quantitative and qualitative methods from October 1-30, 2020. Epi data version 3.1 and SPSS version 25.0 were used for data entry and for analysis respectively. Descriptive statistics and binary logistic regression analysis was employed. Adjusted odds ratios were used to ascertain effect sizes for any association between the dependent and associated variables while significance level at $p$ value of 0.05 was determined using $95 \%$ confidence intervals.

Result: Out of 480 patients included in the study 51\% have Poor self-care practices. About 44.6\%, 92.5\%, 82.8\%, $62.5 \%$ of respondents were poor adherent to antihypertensive medications, low diet quality, poor practiced to physical activity, poor practice to weight management respectively. Some of the respondents $3.3 \%, 9.8 \%$ were smokers and were alcohol drinkers respectively. Educational status who cannot read and write $(A O R=3.153,95 \%$ Cl: $1.674-5.939)$, no co morbidity (AOR $=0.418,95 \% \mathrm{Cl}: 0.263-0.663)$, uncontrolled blood pressure status (AOR = 2.141, 95\% Cl: 1.271-3.609), poor social support status ( $\mathrm{AOR}=2.587,95 \% \mathrm{Cl}: 1.544-4.334)$ and unfavorable attitude (AOR= 3.193, 95\% Cl: 1.951-5.225) showed significant statistical association with poor self-care practice.

Conclusion: The level of hypertension self-care practices found to be low. Therefore, education towards hypertension self-care practices should be strengthened for patients living with hypertension. Special attention should be given to patients with low educational level that cannot read and write, patients with co morbidity, uncontrolled state of hypertension, poor social support and those with unfavorable attitude towards hypertension management modalities.

\section{Background}

Hypertension is persistently elevated blood pressure (BP) in the blood vessels. About $22 \%$ of adults are estimated have in the world (1). Globally, its prevalence continues to grow and is expected to reach 1.56 billion by 2025 with an estimated prevalence of $46 \%$, the African region has the highest prevalence of HTN (2). In Ethiopia, HTN is the peak prevalent non communicable disease with prevalence of $19.6 \%$ (3). When HTN is become uncontrolled which leads to a heart attack and in time heart failure, stroke, kidney failure, blindness and cognitive dysfunction (4). It has been estimated that HTN complications cause about 9.4 million deaths per year, which accounts for 17 percent of the world's total deaths. HTN is responsible for about half of all stroke and heart attack deaths(5). The leading cause of poorly controlled HTN is non-adherence to HTN self-care practice (6). To control and prevent hypertension and its complications self-care practices were crucial and cost-effective measures. Self-Care is Hypertensive patient do for themselves to keep in health and maintain and prevent HNT. HTN self-care requires adherence to medicine, eating a low-fat diet, daily physical exercise, limiting alcohol intake, not smoking, weight loss, BP self-monitoring, regular health care appointments, and reducing stress (7). 
Lifestyle improvements may serve as initial care before the start of drug therapy in hypertensive individuals and as an adjunct to medication in people already on drug therapy. In highly motivated individuals who make and maintain lifestyle improvements, they can encourage drug step-down and drug withdrawal(8). The lifestyle changes can reduce systolic BP by nearly 4 to $11 \mathrm{~mm} \mathrm{Hg}$ with the biggest impacts can be achieved through modifying life style of diet and exercise (4). Also, estimated that for every $1 \mathrm{~kg}$ body weight reduction, there is $1 \mathrm{~mm}$ $\mathrm{Hg}$ BP reduction(8).

Even though HTN is modifiable and treatable, HTN management knowledge in developing countries is very poor. In low-income and middle-income countries, more than $80 \%$ HTN burden is attributed to the lack of knowledge and inadequate practice of self-care(9). Many of Africa's hypertensive patients were unaware of their condition and care(5). Previous studies conducted in Ethiopia found that the prevalence of poor self-care practice was between $77 \%$ (10) and $72.7 \%$ (11), which was high compared to the WHO recommendation that the prevalence of poor HTN self-care should be less than $20 \%$.

Several factors have been associated with adherence to self-care activities, including socioeconomic status, age, gender, educational status, place of residence, co-morbidity, access to health care, level of health literacy, length of therapy, culture, social support, self-efficacy, source of information on self-care \& knowledge of disease \& treatment(12-15). Even though adherence to self-care practices of HTN is an integral part of patient care to achieve the desired therapy goal by improving quality of life, avoiding complication and decrease health care expenditure, the practice of self-care activities in the African population has remained weak. (16). Measuring the level of HTN self-care activities with its determinants has ultimate significance for the creation of successful HTN control strategies. There are some studies in Ethiopia regarding HTN self-care practices. However factors which contribute to poor self-care practice of were not well explored particularly in North West Ethiopia. Hence this study aims to asses' level of hypertension self-care practices and its associated factors among hypertension patients. Also we explore barriers and ways of sustain barriers for self-care practices among hypertensive follow up patients through qualitative case study.

\section{Methods And Materials}

\section{Study setting}

The study was conducted at East Gojjam zone public hospitals. East Gojjam zone is one of the zones found in Amhara region. The zone has an estimated $2,719,118$ population in 2020 .from this $16 \%$ are in urban and $84 \%$ are in rural area. The zone has 21 Districts, one referral hospital, one general hospital, 8 primary hospitals, 102 health centers and 406 health posts with a history of offering HTN services (17).

\section{Study design}

Facility-based quantitative and qualitative methods were applied. Cross-sectional study design and qualitative hypertensive case study with phenomenological study design was conducted.

\section{Source and study population}

All hypertensive patients on follow up at East Gojjam zone public hospitalsare source populations and Hypertensive patients on follow up in the selected hospitals during the study period were study populations. 


\section{Inclusion and Exclusion criteria}

All adult 18 years old and above hypertensive patients on follow up greater than 6 month was included in the study. While Patients who were seriously ill and unable to respond to interview during data collection were excluded from the study.

\section{Sample size determination and sampling procedure}

Sample size was determined by using single population proportion formula for the first objective and double population formula using Epi-info version 7 for second objective. using the assumptions of $95 \%$ confidence interval (Cl), $80 \%$ power, $5 \%$ level of significance, $5 \%$ margin of error ( $d=0.05)$ and $10 \%$ non-response rate. Finally the largest 482 samples was taken as final sample size from Educational status (secondary education) as a significant associated factor from studies(18). For qualitative in-depth interview study 14 in-depth interview was attained the idea saturation. For the quantitative study, $40 \%$ of Hospitals were included in the study. These $40 \%$ hospitals were selected randomly from all hospitals within the zone. One compressive specialized hospital and three primary hospitals was selected for the study. The sample size was allocated to those hospitals proportionally based on the number of hypertension patients with follow-up they had during the data collection period. For quantitative study purposive sampling technique was used to select study participants from the selected Hospitals. Participants were selected based on their willingness to participate in this study and diagnosed with essential HTN for at least twelve months to get their detailed experience of self-care practice.

\section{Outcome measures}

Self-efficacy: Persons confidence in their ability to complete a task. The exposure of self-efficacy to manage HTN is derived from a five item scale. Response options range from 0 (not confident at all) to 5 (totally confident). Respondents who score 4 or above were classified as having good self-efficacy (19).

Social support: Having friends and other people including family to turn to in times of need or crisis to give you a broader focus and positive self-image(20). The Multidimensional Scale of Perceived Social Support (MSPSS) was used to measure subjectively assessed social support. The MSPSS is a 12-item measure of the perceived adequacy of social support on a 7-point Likert-type scale ranging from $1=$ very strongly disagree to $7=$ very strongly agree. The total score range from 12 to 84 with higher score $(\geq 64)$ indicating better perceived social support.

Good self-care practice: When patients respond the mean or above out of the H-SCALE questions. H-SCALE is a self-reported questionnaire that contains six categories of self-care behaviors recommended by the Joint National Committee-8 (JNC- 8) that include medication adherence, low salt diet intake, physical activities, smoking cessation, weight management, and alcohol abstinence.

Medication adherence: there were 3 item questions to measure medication. Then add the responses for items 1-3 (range 0-21). Participants who score a 21 were considered adherent.

Good blood pressure monitoring: BP measurements for controlled HTN with monthly and for uncontrolled one is greater than one per month(21).

Diet quality: were assessed based on DASH-Q (11 items); these items assess intake of healthy foods associated with the nutritional composition of the DASH diet. Responses were summed. The range should be 0 to 77 . Scores 
of 32 and below were considered low diet quality; scores between 33 and 51 were medium diet quality and scores of 52 or greater considered adherent.

Physical Activity: two items were assessed physical activity. Responses were summed (range 0-14). Participants who score 8 or above were considered adherent to physical activity recommendations; all others were nonadherent.

Smoking adherence: 2 items were assessed smoking. Responses were summed (range 0 to 14). Respondents who score zero was considered adherent.

Weight Management (10 items; 19-28) - These 10 items assess activities undertaken to manage weight. Items assessed activities during the past 30 days. Response categories range from strongly disagree (1) to strongly agree (5). Sum the responses to calculate the score with a range from 10-50. Participants who reported score $\geq 40$ were considered to be adherent to good weight management practices.

Alcohol (3 items; 29-31) - Alcohol intake were assessed using 3-item Participants who report not drinking any alcohol in the last 7 days or who indicate that they usually did not drink at all was considered abstainers. All others was considered as not having a good practice of alcohol consumption.

Knowledgeable: When participants answer median or above out of the knowledge questions.

Favorable attitude: When patients respond the median or above out of the attitude questions.

Optimally controlled BP: An average systolic BP $<130$ and diastolic BP $<80 \mathrm{mmHg}$ for at least three consecutive follow-up appointments in patients younger than 60 years old (22).

\section{Data collection tool and methods}

Data was collected by interviewer-administered questionnaire. The questionnaire was adapted from previous literatures and modified to the context of this study. The questioner have eight parts; Part I: Socio demographic information(9Q), Part II: Health profile of patient questions(8Q), Part III : questions related with the source of information about non pharmacological self-care practices(5Q), Part IV: Knowledge questions(12Q), Part V: Attitude questions(10Q), Part VI: Self-efficacy measure questions(5Q), Part VII: Social support questions(12Q), Part VIII: H-SCALE questions(31Q). The questionnaire was pretested among HTN patients who had follow up from hospitals other than the study area but having the same characteristics. Five trained clinical nurses and two BSC Nurse Supervisors collected data through a face-to-face interview. For the qualitative part Responses were collected through individual face-to-face in-depth semi structured probing question interviews by using interview guide questions that contains five items. The interviews were record on an audio recorder and hand-written notes were taken to assist with analysis of the transcribe data.

\section{Data processing and Analysis}

For quantitative study the collected data were coded and entered into Epi data version 3.1 and cleaned and transferred to SPSS version 25.0 statistical software for further analysis. Various types of descriptive statistics such as mean, median, interquartile range, proportions and cross-tabulations were used to present study variables. Factors associated with self-care practices were identified using bivariate and multivariable logistic regression analysis. Covariates and logistic regression assumptions were checked using a Hosmer-Lemeshow test and 
goodness of fit by VIF test. Associations were described using odds ratio at $95 \% \mathrm{Cl}$ and statistical test was considered significant at a $\mathrm{P}$ value of less than 0.05 . For qualitative study all the interviews were transcribe verbatim immediately and data was analyzed using thematic content analysis methods manually.

\section{Ethical considerations}

Ethical approval for the study was obtained from Debre Markos University health Science College, ethical review committee and supporting letter was obtained from selected hospital administration. Data was collected after informed verbal consent is obtained from the participants. Confidentiality of the information was maintained by excluding names as identification in the questionnaire \& keeping their privacy during the data collection.

\section{Result}

\section{Socio-demographic characteristics}

Out of the total 482 respondents, 480 participated in the study, yielding a response rate of $99.6 \%$. The mean age of the respondents was $55.4(\mathrm{SD} \pm 11.2)$ years. More than half $(55.6 \%)$ of the respondents were male and most $394(82.1 \%)$ of the respondents were married. About $396(82.5 \%)$ of respondents were Follower of Orthodox religion. Nearly all (99\%) of the respondents were Amhara in ethnicity. About 293(61\%) of respondents had no formal education and $314(65.4 \%$ ) of the respondents resided at urban (Table 1).

\section{Health profile of respondents}

From the total respondents $228(47.5 \%)$ participants had family history of HTN and more than half of the participants $258(53.7 \%)$ were over weighted and obese. About 216 respondents $(45 \%)$ have uncontrolled HTN. About $231(48.1 \%$ ) respondents have co morbidity in addition to HTN. Nearly one third $160(33.3 \%)$ of respondents have treatment duration of 5 years and above. About $130(27.1 \%)$ of respondents miss their follow up visit from health institutions (Table 2).

\section{Source of information of HTN self-care practice findings}

More than half of respondents 295 (61.5\%) were heard about the non-medical management of HTN. From these $253(85.8 \%)$ respondents' get the information from health workers. During their follow up time, 198 (41.3\%) of the study participants were not get any information towards the non-medical management of HTN (Table 3 ).

\section{Individual related findings}

About $282(58.8 \%)$ of the participants have good knowledge about HTN self-care practice and $243(50.6 \%)$ of the participants had favorable attitude towards HTN self-care practice. More than half $279(58.1 \%)$ of participants have good self-efficacy and 227(47.3\%) have poor social support (table 4).

\section{Level of hypertension self-care practices}

The median score for self-care practice was 72 with maximum score of 133. Out of the total respondents, $245(51.0 \%)$ patients had poor self-care practice with $95 \% \mathrm{Cl}(46.56 \%, 55.51 \%)$. The median score for medication adherence was 21 with the maximum score of 24 . About $214(44.6 \%)$ of respondents practiced poor adherent to antihypertensive medications. The median score for good practice to diet was 10 with maximum score of 57 . Most 
of the participants $444(92.5 \%)$ practiced low diet quality, 32(6.7\%) practiced medium diet quality and $4(0.8 \%)$ practiced good diet quality. The median score for physical activity was 4 with the maximum score of 14 . About $398(82.8 \%)$ respondents' poor practiced to physical activity. The median score of weight management practice of the participants were 38 with the maximum score of 50 . More than half of respondents 300 (62.5\%) had poor weight management practice. Few number of participants $16(3.3 \%)$ were smokers and $47(9.8 \%)$ were drunk alcohol (Figure 1).

\section{Factors associated with self-care practice}

From all 26 variables, 4 variables (treatment duration, source of information, information per follow up visit, information clearness in follow up visit) were not included in regression analysis due to system missing and Multicollinearity problems. The final multivariable logistic regression analysis revealed Educational level, co morbidity, BP control status, attitude and social support were independent factors for self-care practices of HTN Patients. Patients who cannot read and write were 3.153 times more likely practice poor self-care $(A O R=3.153$, 95\% Cl: 1.674-5.939) as compared to those patients having grade12 and above educational level. Individuals with uncontrolled BP state were 2.141times more likely to practice poor self-care (AOR $=2.141,95 \% \mathrm{Cl}$ : $1.271-3.609)$ as compared to those who had controlled state of BP. Patients who had no co-morbidity were $58.2 \%$ times less likely to practice poor self-care ( $\mathrm{AOR}=0.418,95 \% \mathrm{Cl}: 0.263-0.663$ ) as compared to those with co-morbidity. Patients who had unfavorable attitude were 3.193 times more likely to practice poor self-care (AOR=3.193, 95\% Cl: 1.951-5.225) as compared to those patients with favorable attitude. On the other hand, hypertensive patients with poor social support were 2.587 times more likely to practice poor self-care practice (AOR $=2.587,95 \% \mathrm{Cl}: 1.544-4.334)$ as compared to patients with good social support (Table 5).

\section{Qualitative section}

A total of fourteen in-depth interviews were conducted until the data saturation was attained. All participants have HTN for at least two years. Nine of the participants were female. All respondents were between the age of 30 and 80 years, and seven of them were married. With regard to their educational back ground, one has attended college, three had secondary education, one could write and read only and nine of them were not read and write. Among the participants, 13 were orthodox religion and one was Muslim religion followers. After all in-depth interviews completed we categorized in to 3 thematic areas. The first theme explores barriers to participating in the self-care practice activities. The second theme explores challenges of sustaining self-care management activities. The third theme describes effect of HTN on lifestyle.

\section{Theme 1: Barriers to participating in the self-care practice activities}

Family meal preparation habits were identified as a barrier for self-care practice as expressed by the respondents:

" it is so challenging to prepare food separately for me out of my family. Even my family feels unhappy when they prepare without salt..." 34-year-old male respondent

Inadequate information on HTN and its self are practice by the doctor at follow up visit were recognized as barriers; as stated by a respondent:

“...... I've stopped taking medication for 1 year. I don't do anything special right now. I drink coffee, I use salt, I don't know what BP control is.... " 55-year-old female respondent" 
... after I take pills for BP, my BP became normal and after that no need of taking drugs..." 65 year old man.

The inconvenience working environment also mentioned as barrier which well explored by the respondents

"....Even if I was committed to regular exercise, it is not convenient. There is no place to exercise...." 60-year-old man.

\section{Theme 2: Challenges of sustaining self-care management activities}

Pressure during social events, sharing food during social gathering in Ethiopia is considered a way of expressing respect and affection to one another and refusing is unacceptable; as stated by a respondent:

"...When I go to Senbete and Mahiber (social event in Ethiopia). With pleasure, I take what they offer me because it's not necessary to deny. That's why l eat what they have prepared. A social life for us is important........" 45-year-old male participant.

It was difficult to prepare individual meals for one person in a family. Ethiopian culture does not allow men to engage in the preparation of food. As mentioned by a respondent, a man with HTN must eat whatever is served to the family:

"... I eat what my wife and children eat. It is difficult to prepare a separate meal just for myself; you know it just is not convenient...." 76-year-old male participant.

The patients recognized that negligence and poor self-efficacy to practice self-care activity was also challenges; as stated by a respondent:

".....poor controlling of my BP is the problem of me that I am not giving attention for life styles....."60 year-old male participant.

"I don't exercise regularly. I walk sometimes on the street when I have the time but scheduled sport is not practiced...." 34-year-old women.

"Exercise at my age?! I cannot think it. It is difficult . .." 77-year-old women.

\section{Theme 3: Effect of HTN on lifestyle}

The patients believed that the diagnosis of HTN had profound effect on their lifestyle; change of lifestyle after diagnosis of HTN requires discipline and motivation; as stated by a respondent:

".... I can't eat as much as I want. I have a lot of family work load to prepare food...." 51-year-old female participant.

"....It is challenging to cope with very challenging life, difficult to work hard due to pain and selective way of diet consumption for HTN management....."36-year-old female participant.

\section{Discussion}

This research sought to determine the prevalence of self-care in hypertensive patients in terms of adherence to antihypertensive drugs and lifestyle improvements. The overall prevalence level of self-care practice in this study was $51 \%$ with $95 \% \mathrm{Cl}(46.55,55.51)$. This was in line with a study conducted at Jimma hospital which was $55.3 \%$ 
(23) and Nigeria which was $47.4 \%$ (24). However, the result of this study was lower than a study conducted at Mizan Tepi hospital which was 66.7\%(25), Durame hospital which was 72.7\%(16), and Addis Ababa which was $77 \%(10)$. In contrast, the finding of this study was higher than a study conducted at Hiwot Fana and Jugola hospital which was $37.9 \%$ (26), Nekemite hospital (27) which was 31.1\%, Saudi which was 25.6\% (33), Ghana which was $28 \%$ (35) and Iran which was $27 \%(28)$. This discrepancy might be due to differences in life style, culture, economic status, access to health care facilities and level of education of the general public. In addition, difference in level of knowledge about self-care practice among HTN patients across the region and countries; the level of understanding of health care workers on HTN self-care practices may contribute to the variation of HTN self-care practices across the countries. Furthermore, difference in level of HTN self-care education given at different health care facilities may also be contributing to the variation of findings.

The prevalence of low diet quality in this study was $92.5 \%$ with $95 \% \mathrm{Cl}(89.76 \%, 94.54 \%)$. This finding was higher than a studies done at Durame 42.5\% (16), at Hiwot Fana and Jugola 18.2\%(26), at Saudi 20.7\% (29) and Uganda $24.4 \%$. (30). This might be due to the difference in dietary habits awareness of diet management across the region and the country. Also, the difference in measurement tool, socioeconomic and socio cultural values can be the source of variations of the finding. This also, supported by the qualitative part of this study revealed as variety of food with fruit and vegetable was not affordable and does not given emphasis.

In this study non adherence to physical activity was $82.8 \%$ with $95 \% \mathrm{Cl}(79.26 \%, 86.03 \%)$. This was in line with a study done at Durame which was $83.9 \%$ (16). But, This finding was higher than studies done at Addis Ababa $68.6 \%$ and $50.6 \%(6,31)$ and Saudi $76.8 \%(29)$. Similarly, the qualitative part of this study has shown that poor physical activity was most important task in the self-care of hypertension. This might be due to limited or lack of structured setting for physical exercise around the work places as well as in the general public at the study area. Moreover the patient's awareness and attitude towards physical activity can limit their practice.

The prevalence of smoking in this study was 3.3\% with $95 \% \mathrm{Cl}(2.05 \%, 5.38 \%)$. this finding was lower than a study done at Durame (16) which was 8.8\%, Hiwot Fana (26) which was 18.5\%, India (32) which was $11 \%$, Kenya which was $8.3 \%$ (33) different part of Nigeria which was $15.4 \%$ and $12.2 \%(34,35)$ Canada which was $22 \%$ (36),Korea which was $34.2 \%$ (37), Iran which was $15.3 \%$ (38). Also, the prevalence of alcohol consumption in this study was $9.8 \%$ with $95 \% \mathrm{Cl}(7.42 \%, 12.80 \%)$. This was in line with a study conducted at Jimma (15) which was $11.7 \%$ and Durame (16) which was $12.1 \%$. however this finding was much lower than studies conducted at different part of Nigeria which was $28.7 \%$ and $21.7 \%(34,35)$, Ghana which was $15.7 \%$ (39) ,Kenya which was $13.1 \%(33)$, Korea which was $36.6 \%$ (37).the variation of the findings might be due to difference in socio cultural and religious perspectives. In the current study area smoking and alcohol consumption is highly discouraged within the community.

Patients who cannot read and write were 3.153 times more likely practice poor self-care as compared to those grades 12 and above educational level. This was in line with study at Durame (16) and Ayder hospitals (40). This is due to cognitive differences between patients who are unable to read and write and higher education level. Patients who cannot read and write miss the information sources like posters, leaflets and other written material that assist HTN self-care practice.

Patients who had no co-morbidity were $41.8 \%$ more likely practice self-care activities than patients with comorbidity. This finding was consistent with the study done at Addis Ababa (31), Durame (16) and study done at Ayder Hospitals (41). This might be due to symptoms of their comorbid conditions or lifestyle changes

Page $9 / 19$ 
necessitated by their comorbid conditions interfered with self-care for hypertension. Also, Co-morbidities will exacerbate the patient's symptoms and make them unable to adapt to lifestyle changes (42).

In this study, Individuals with uncontrolled BP state were 2.141times more likely to practice poor self-care as compared to those who had controlled state of BP. This was in line with a study done at Hiwot Fana and Jugola Hospital Harare, Ethiopia (26) and study done at Ayder hospital (40) this might be due to the fact that good selfcare practice can control blood pressure.

The study also showed that hypertensive patients with poor social support were 2.587 times more likely to practice poor self-care practice as compared to patients with good social support. This was in line with study done at Desse town public hospital and health centers, Ethiopia (18), at selected public hospitals of Addis Ababa (31) and at Jimma hospital (15). This might be due to Social support can encompasses multiple dimensions that positively influence patients life style modification through having regular follow up visit, managing stress and psychologically active to self-care-practice.

The study also depicted that; attitude was significantly associated self-care practice. Patients who had unfavorable attitude were 3.193 times more likely practice poor self-care as compared to those patients with favorable attitude. In addition the qualitative part of this study revealed that unfavorable attitude towards self-care practice leads to high BP that results to the development of symptoms and complication of HTN. This might be due to patients having favorable attitude towards HTN can understand the complications of the disease, so that they practice self-care activities effectively in order to prevent those complications.

\section{Limitation of the study}

Hypertensive patients attending follow-up in health centers were not included in the study. Research methodologies involving self-reported measures depend largely on individuals' memory recall bias and denial of poor practices from the respondents may exist which affects the result of the study.

\section{Conclusion}

The level of self-care practice found to low compared to WHO standard. Particularly dietary approach to stop HTN, physical exercise and weight management was very low. Patients who cannot read and write, have uncontrolled state of BP, poor social support and unfavorable attitude and co morbidity were significantly associated with HTN self-care practice. The pressure during social events, Preparing separate meals for one person in a family, negligence and temptations were recognized challenges for HTN self-care practice. Therefore, designing policies towards improving and modifying education of HTN self-care practices should be made. Special attention should be given to patients with low educational level, patients with additional co morbidity, uncontrolled state of HTN, poor social support and those with unfavorable attitude towards hypertension management modalities. In addition, assessing and close monitoring of HTN self-care practice at every follow up visit should be conducted to address their gaps.

\section{Abbreviations}

AOR: Adjusted odd ratio, BP: blood pressure, BMI: body mass index, COR: crude odd ratio, DASH diet: HTN: hypertension, H-scale: SD: Standard deviation, IQR: Interquartile range, Cl: Confidence interval, VIF: variance inflation factor, WHO: world health organization

Page $10 / 19$ 


\section{Declarations}

\section{Ethical approval and consent to participate}

Ethical approval for the study was obtained from Debre Markos University health Science College, ethical review committee and supporting letter was obtained from selected hospital administration. Data was collected after informed verbal consent is obtained from the participants. Confidentiality of the information was maintained by excluding names as identification in the questionnaire \& keeping their privacy during the data collection

\section{Authors' contributions}

$\mathrm{BA}$ and $\mathrm{HZ}$ performed the analysis and interpretations. TS wrote the first draft, BA, $\mathrm{HZ}$ \& NM contributed to the design of the study and substantive revision of the final draft. All authors read and approved the final manuscript.

\section{Funding}

The work was supported by Debre-Markos University, College of health sciences. The content is solely the responsibility of the authors and does not necessarily represent the official views of the funders. The funders had no role in study design, data collection, and analysis, decision to publish, or preparation of the manuscript.

\section{Availability of data and materials}

All materials and data are available from the corresponding author without any restriction.

\section{Consent for publication}

Not applicable.

\section{Competing interests}

The authors declare that they have no competing interests.

\section{Acknowledgment}

We would like to express our great thanks to Debre-Markos University, College of health science for their willingness and support. Next, our great thanks also go to hospital administrators of study area. Lastly, we acknowledge our data collectors, supervisors, and friends that support us throughout our work.

\section{References}

1. Whelton PK, Carey RM, Aronow WS, Casey DE, Jr., Collins KJ, Dennison Himmelfarb C, et al. 2017 ACC/AHA/AAPA/ABC/ACPM/AGS/APhA/ASH/ASPC/NMA/PCNA Guideline for the Prevention, Detection, Evaluation, and Management of High Blood Pressure in Adults: Executive Summary: A Report of the American College of Cardiology/American Heart Association Task Force on Clinical Practice Guidelines. Hypertension (Dallas, Tex : 1979). 2018;71(6):1269-324.

2. WHO. A global brief on Hypertension. WHO. 2013.

3. Kibret KT, Mesfin YM. Prevalence of hypertension in Ethiopia: a systematic meta-analysis. Public Health Reviews. 2015;36(1):14. 
4. Dorans KS, Mills KT, Liu Y, He J. Trends in Prevalence and Control of Hypertension According to the 2017 American College of Cardiology/American Heart Association (ACC/AHA) Guideline. Journal of the American Heart Association. 2018;7(11).

5. World Health Organization. Regional Office for the Eastern Mediterranean. (2013). World Health Day 2013 : control your blood pressure .. control your life: high blood pressure control it with legislation. https://apps.who.int/iris/handle/10665/113247.

6. Bacha D, Abera H. Knowledge, Attitude and Self-Care Practice towards Control of Hypertension among Hypertensive Patients on Follow-up at St. Paul's Hospital, Addis Ababa. Ethiopian journal of health sciences. 2019;29(4):421-30.

7. Williams B, Mancia G, Spiering W, Agabiti Rosei E, Azizi M, Burnier M, et al. 2018 ESC/ESH Guidelines for the management of arterial hypertension. European heart journal. 2018;39(33):3021-104.

8. Vanitha D, Anitha Rani.M Knowledge and Practice on lifestyle modifications among males with hypertension.Indian J Comm Health. 2015; 27, 1: 143-149.

9. Mengistu MD. Pattern of blood pressure distribution and prevalence of hypertension and prehypertension among adults in Northern Ethiopia: disclosing the hidden burden. BMC Cardiovascular Disorders. 2014;14(1):33.

10. Tibebu A, Mengistu D, Negesa L. Adherence to recommended lifestyle modifications and factors associated for hypertensive patients attending chronic follow-up units of selected public hospitals in Addis Ababa, Ethiopia. Patient Prefer Adherence. 2017;11:323-30.

11. Buda ES, Hanfore LK, Fite RO, Buda AS. Lifestyle modification practice and associated factors among diagnosed hypertensive patients in selected hospitals, South Ethiopia. Clinical Hypertension. 2017;23(1):26.

12. H. Hu GL, and T. Arao,. "Prevalence rates of self-care behaviors and related factors in a rural hypertension population: a questionnaire survey," International Journal of Hypertension,. 2013.; vol. 2013(Article ID 526949, ):8 pages,.

13. Motlagh SFZ CR, Sadeghi E, Eslami AA. Self-care behaviors and related factors in hypertensive patients. . Iranian Red Crescent Medical Journal. 2016;18(6).

14. Beigi MAB ZM, Aghasadeghi K, Jokar A, Shekarforoush S, Khazraei H. The effect of educational programs on hypertension management. Int Cardiovasc Res J. 2014;8(3):94-8.

15. Busha Gamachu Labata MBA, Ginenus Fekadu Mekonen and Fekede Bekele Daba. Prevalence and predictors of self care practices among hypertensive patients at Jimma University Specialized Hospital,Southwest Ethiopia: cross-sectional study. BMC. 2019.

16. Eyasu Siyum Buda LKH, Robera Olana Fite and Alula Seyum Buda. Lifestyle modification practice and associated factors among diagnosed hypertensive patients in selected hospitals,South Ethiopia. Biomed Central. 2017.

17. East Gojjam Zone Hod. East Gojjam Zone Health Department Six Month Report. 2020.

18. Sewunet Ademe FAaDG. Hypertension self-care practice and associated factors among patients in public health facilities of Dessie town, Ethiopia. BMC Health Services Research. 2019.

19. Warren-Findlow J, Seymour RB, Huber LRB. The association between self-efficacy and hypertension self-care activities among African American adults. Journal of community health. 2012;37(1):15-24.

20. Mcdowell. Measuring health: a guide to rating scales. . Stat Med. 1989;8:1308-9. 
21. Organization WH. Technical package for cardiovascular disease management in primary health care. WHO. 2018.

22. Association AH. A Report of American Heart Association Task Force on Clinical Practice Guidelines. Report. 2017.

23. Anwar Abdulwahed AS, Ebrahim Yimam. Level of self-care practice and associated factors among hypertensive patients in Jimma University Specialized Hospital, south west Ethiopia. Unpublished 2016.

24. Rachael Oluwafunmilayo Ajiboye NAO, Ibironke Ojo Abiodun. Knowledge and Practice of Lifestyle Modification among Hypertensive Patients in a General Hospital Lagos. IOSR Journal of Nursing and Health Science (IOSR-JNHS). 2020;9(2).

25. Ermias ATT. Lifestyle modification practice and associated factors among diagnosed hypertensive patients in Mizan Tepi University Teaching Hospital South west Ethiopia PAMJ Clinical Medicine. 2019;2.

26. Nadewu AN GB. Adherence to Healthy Lifestyle among Hypertensive Patients in Harar Region, Eastern Ethiopia. . Prim Health Care. 2018;8(doi: 10.4172/2167-1079.1000308):308.

27. Fetensa G MN, Besho M, Hasen T, Teshoma M, Wakuma B, Etefa W and Fayisa L. Assessment of Knowledge and Practice of Life Style Modification among Hypertensive Patients at Nekemte Specialized Hospital, Western Oromia. Journal of Cardiovascular Diseases \& Diagnosis. 2019.

28. Khorsandi M, Roozbahani N, zade zf, editors. A Survey on Health Beliefs Relation with Self - Care Practice among the Elderly Hypertension in Iran (2013)2014.

29. Lama A. Bakhsh AAA, Maradi A. Murad, Rana M. Nourah, Sulaiman A.Hanbazazah, Aseel A. Aljahdali, Reem J. Alshareef. Awareness and Knowledge on Hypertension and its SelfCare Practices Among Hypertensive Patients in Saudi Arabia. Annals of International Medical and Dental Research. 2017;3(5).

30. Andrew K Tusubira CKN, Ann R Akiteng, et al. Self-care practices and needs in patients with hypertension, diabetes, or both in rural Uganda: a mixed-methods study. UINCD. 2020.

31. Abel Tibebu DM, Lemma Negesa. Adherence to recommended lifestyle modifications and factors associated for hypertensive patients attending chronic follow-up units of selected public hospitals in Addis Ababa, Ethiopia. Dovepress. 2017;11 323-30.

32. Vanitha D ARM. Knowledge and Practice on lifestyle modifications among males with hypertension. Indian J Comm Health 2015;27

33. Kimani S, Mirie W, Chege M, Okube OT, Muniu S. Association of lifestyle modification and pharmacological adherence on blood pressure control among patients with hypertension at Kenyatta National Hospital, Kenya: a cross-sectional study. BMJ open. 2019;9(1):e023995.

34. Ezeala-Adikaibe BA1, Mbadiwe N1,2, Okudo G,et al. Factors Associated with Medication Adherence among hypertensive Patients in a Tertiary Health Center: A Cross-Sectional Study. Archives of Community Medicine and Public Health. (2455-5479).

35. Adisa R, llesanmi OA, Fakeye TO. Treatment adherence and blood pressure outcome among hypertensive outpatients in two tertiary hospitals in Sokoto, Northwestern Nigeria. BMC cardiovascular disorders. 2018;18(1):194-.

36. Gee ME, Bienek A, Campbell NR, Bancej CM, Robitaille C, Kaczorowski J, et al. Prevalence of, and barriers to, preventive lifestyle behaviors in hypertension (from a national survey of Canadians with hypertension). The American journal of cardiology. 2012;109(4):570-5.

Page 13/19 
37. Yang MH, Kang SY, Lee JA, Kim YS, Sung EJ, Lee K-Y, et al. The Effect of Lifestyle Changes on Blood Pressure Control among Hypertensive Patients. Korean J Fam Med. 2017;38(4):173-80.

38. Akbarpour S, Khalili D, Zeraati H, Mansournia MA, Ramezankhani A, Fotouhi A. Healthy lifestyle behaviors and control of hypertension among adult hypertensive patients. Scientific Reports. 2018;8(1):8508.

39. Obirikorang, Y. , Obirikorang, C. , Acheampong, E. , Anto, E. , Amoah, B. , Fosu, E. , Amehere, J. , Batu, E. , Brenya, P. , Amankwaa, B. , Adu, E. , Akwasi, A. and Asiwu, R. (2018) Adherence to Lifestyle Modification among Hypertensive Clients: A Descriptive Cross-Sectional Study. Open Access Library Journal, 5, 1-13. doi: 10.4236/oalib.1104375.

40. Gebrewahd Bezabh Gebremichael KKB. Self-care practices and associated factors among adult hypertensive patients in Ayder Comprehensive Specialized Hospital, Tigray,Ethiopia. BMC 2019;12:489.

41. Yirga Legesse Niriayo SI, Tesfaye Dessale Kassa, et al . Practice and predictors of self-care behaviors among ambulatory patients with hypertension in Ethiopia. PLoS ONE 2019;14(6):(e0218947.).

42. Bryan Williams GM, Wilko Spiering et al. Guidelines for themanagement of arterial hypertension. European Heart Journal 2018;39.

\section{Tables}


Table 1

Socio demographic characteristics of participants of hypertensive follow up patients at East Gojjam Zone public hospitals, North West Ethiopia October 1-

30,2020

\begin{tabular}{|c|c|c|c|}
\hline Variable Name & & Frequency & Percent \\
\hline \multirow[t]{3}{*}{ Age } & 18-39yr & 38 & 7.9 \\
\hline & $40-60 y r$ & 303 & 63.1 \\
\hline & $>60 y r$ & 139 & 23.0 \\
\hline \multirow[t]{2}{*}{ Sex } & Male & 267 & 55.6 \\
\hline & Female & 213 & 44.4 \\
\hline \multirow[t]{2}{*}{ Ethnicity } & Amhara & 475 & 99.0 \\
\hline & Oromo & 5 & 1.0 \\
\hline \multirow[t]{5}{*}{ Educational status } & Unable to read \& write & 196 & 40.8 \\
\hline & Read \& write only & 97 & 20.2 \\
\hline & Grade 1-8 & 38 & 7.9 \\
\hline & Grade 9-12 & 48 & 10 \\
\hline & Grade 12 and above & 101 & 21 \\
\hline \multirow[t]{4}{*}{ Marital status } & Single & 10 & 2.1 \\
\hline & Married & 394 & 82.1 \\
\hline & Divorced & 24 & 5 \\
\hline & Widowed & 52 & 10.8 \\
\hline \multirow[t]{3}{*}{ Religion } & Orthodox Christian & 396 & 82.5 \\
\hline & Muslim & 82 & 17.1 \\
\hline & Protestant & 2 & 0.4 \\
\hline \multirow[t]{2}{*}{ Occupation } & Employed & 107 & 22.3 \\
\hline & Unemployed & 373 & 77.7 \\
\hline \multirow[t]{2}{*}{ Residence } & Urban & 314 & 65.4 \\
\hline & Rural & 166 & 34.6 \\
\hline \multirow[t]{2}{*}{ Average monthly Income } & $\leq 1000$ ETB & 213 & 44.4 \\
\hline & $>1000$ ETB & 267 & 55.6 \\
\hline
\end{tabular}


Table 2

Health profile characteristics of respondents for self-care practice of hypertensive follow up patients at East Gojjam Zone public hospitals, North West Ethiopia October 1-30, 2020

\begin{tabular}{|c|c|c|c|}
\hline Variables & & Frequency & Percent \\
\hline \multirow[t]{2}{*}{ Family history of HTN } & Yes & 228 & 47.5 \\
\hline & No & 252 & 52.5 \\
\hline \multirow[t]{4}{*}{ BMI } & Underweight(<18.5) & 3 & 0.6 \\
\hline & Normal (18.5-24.99) & 219 & 45.6 \\
\hline & Overweight (25-29.99) & 243 & 50.6 \\
\hline & Obese(30-39.99) & 15 & 3.1 \\
\hline \multirow[t]{4}{*}{ BP monitoring schedule status } & Two times per month & 4 & 0.8 \\
\hline & One monthly & 329 & 68.5 \\
\hline & Two monthly & 146 & 30.4 \\
\hline & Three monthly & 1 & 0.2 \\
\hline \multirow[t]{2}{*}{ BP Status } & Controlled & 264 & 55 \\
\hline & Uncontrolled & 216 & 45 \\
\hline \multirow[t]{2}{*}{ Co morbidity } & Yes & 231 & 48.1 \\
\hline & No & 249 & 51.9 \\
\hline \multirow[t]{3}{*}{ Disease duration since diagnosis } & $<2$ years & 116 & 24.2 \\
\hline & $2-4$ years & 131 & 27.3 \\
\hline & $\geq 4$ years & 233 & 48.5 \\
\hline \multirow[t]{2}{*}{ Treatment duration since diagnosis } & $<5$ years & 320 & 66.7 \\
\hline & $\geq 5$ years & 160 & 33.3 \\
\hline \multirow[t]{2}{*}{ Miss follow up } & Yes & 130 & 27.1 \\
\hline & No & 350 & 72.9 \\
\hline
\end{tabular}


Table 3

Source of information related finding of self-care practice of hypertensive follow up patients at East Gojjam Zone, North West Ethiopia October 1-30, 2020.

\begin{tabular}{|c|c|c|c|}
\hline Variables & & Frequency & Percent \\
\hline \multirow{2}{*}{$\begin{array}{l}\text { Have you ever heard the non-medical management of HTN for HTN } \\
\text { patients? }\end{array}$} & Yes & 295 & 61.5 \\
\hline & No & 185 & 38.5 \\
\hline \multirow[t]{4}{*}{ What is the source of information? } & $\begin{array}{l}\text { Health } \\
\text { worker }\end{array}$ & 253 & 85.8 \\
\hline & Media & 16 & 5.4 \\
\hline & Relatives & 25 & 8.5 \\
\hline & Books & 1 & 0.3 \\
\hline \multirow{2}{*}{$\begin{array}{l}\text { Is there any info given towards the non-medical management of } \\
\text { HTN in your f/ up clinic? }\end{array}$} & Yes & 282 & 58.8 \\
\hline & No & 198 & 41.3 \\
\hline \multirow{2}{*}{$\begin{array}{l}\text { Do you get info about the non-medical management of HTN at each } \\
\text { visit? }(N=282)\end{array}$} & Yes & 271 & 96.1 \\
\hline & No & 11 & 3.9 \\
\hline \multirow{2}{*}{$\begin{array}{l}\text { Is the info given in the follow up clinic understandable to you? } \\
(\mathrm{N}=282)\end{array}$} & Yes & 276 & 97.9 \\
\hline & No & 6 & 2.1 \\
\hline
\end{tabular}

Table 4

Individual related finding of self-care practice of hypertensive follow up patients at East Gojjam Zone, North West Ethiopia October 1 -30, 2020.

\begin{tabular}{|llll|}
\hline Knowledge towards self-care practice of hypertensive & Good & 282 & 58.8 \\
\cline { 2 - 4 } & Poor & 198 & 41.3 \\
\hline Attitude of patient towards self-care practice of hypertensive & Favorable & 243 & 50.6 \\
\cline { 2 - 4 } & Unfavorable & 237 & 49.4 \\
\hline Self-efficacy & Good & 279 & 58.1 \\
\hline Social support & Poor & 201 & 41.9 \\
\hline & Good & 253 & 52.7 \\
\cline { 2 - 4 } & Poor & 227 & 47.3 \\
\hline
\end{tabular}


Table 5

Association of variables to self-care practice of hypertensive patients at East Gojjam Zone, North West Ethiopia October 1-30, 2020.

\begin{tabular}{|c|c|c|c|c|c|c|}
\hline \multirow[t]{2}{*}{ Variables } & & \multicolumn{2}{|c|}{ Self-care practice } & \multirow{2}{*}{$\begin{array}{l}\text { Crude odds ratio } \\
\text { (COR) With } 95 \% \mathrm{Cl}\end{array}$} & \multirow{2}{*}{$\begin{array}{l}\text { Adjusted odds } \\
\text { ratio(AOR) With } \\
95 \% \mathrm{Cl}\end{array}$} & \multirow{2}{*}{$\begin{array}{l}\text { P- } \\
\text { Value }\end{array}$} \\
\hline & & $\begin{array}{l}\text { Poor N } \\
(\%)\end{array}$ & $\begin{array}{l}\text { Good N } \\
(\%)\end{array}$ & & & \\
\hline \multirow[t]{5}{*}{$\begin{array}{l}\text { Educational } \\
\text { status }\end{array}$} & $\begin{array}{l}\text { Can't read } \\
\text { \&write }\end{array}$ & 133(27.7) & $63(13.1)$ & $6.418(3.731,11.038)$ & $3.153(1.674,5.939)$ & $<0.001$ \\
\hline & $\begin{array}{l}\text { Write and } \\
\text { read only }\end{array}$ & $52(10.8)$ & $45(9.4)$ & $3.513(1.922,6.419)$ & $1.665(0.809,3.427)$ & 0.166 \\
\hline & $\begin{array}{l}\text { Primary } \\
\text { education }\end{array}$ & $17(3.5)$ & $21(4.4)$ & $2.461(1.125,5.385)$ & $1.624(0.627,4.210)$ & 0.318 \\
\hline & $\begin{array}{l}\text { Secondary } \\
\text { education }\end{array}$ & 18(3.8) & $30(6.3)$ & $1.824(0.871,3.818)$ & $0.534(0.209,1.363)$ & 0.189 \\
\hline & $\begin{array}{l}\text { Grade } 12 \\
\text { and above }\end{array}$ & $25(5.2)$ & $76(15.8)$ & 1 & 1 & \\
\hline \multirow[t]{2}{*}{ BP Status } & Uncontrolled & 163(34) & $53(11)$ & $6.826(4.553,10.234)$ & $2.141(1.271,3.609)$ & 0.004 \\
\hline & Controlled & $82(17.1)$ & 182(37.9) & 1 & 1 & \\
\hline \multirow{2}{*}{$\begin{array}{l}\text { Co } \\
\text { morbidity } \\
\text { status }\end{array}$} & Yes & 150(31.3) & 81(16.9) & 1 & 1 & \\
\hline & No & 95(19.6) & 154(32.1) & $0.333(0.230,0.483)$ & $0.418(0.263,0.663)$ & $<0.001$ \\
\hline \multirow{2}{*}{$\begin{array}{l}\text { Miss follow } \\
\text { up }\end{array}$} & Yes & 102(21.3) & $28(5.8)$ & 1 & 1 & \\
\hline & No & $143(29.8)$ & 207(43.1) & $5.273(3.298,8.432)$ & $0.589(0.327,1.061)$ & 0.078 \\
\hline \multirow[t]{2}{*}{ Attitude } & Unfavorable & 176(36.7) & $61(12.7)$ & $7.276(4.862,10.889)$ & $3.193(1.951,5.225)$ & $<0.001$ \\
\hline & Favorable & $69(14.4)$ & $174(36.3)$ & 1 & 1 & \\
\hline \multirow{2}{*}{$\begin{array}{l}\text { Social } \\
\text { support }\end{array}$} & Poor & $170(35.4)$ & $57(11.9)$ & 7.078(4.728,10.596) & $2.587(1.544,4.334)$ & $<0.001$ \\
\hline & Good & $75(15.6)$ & 178(37.1) & 1 & 1 & \\
\hline
\end{tabular}

Figures 


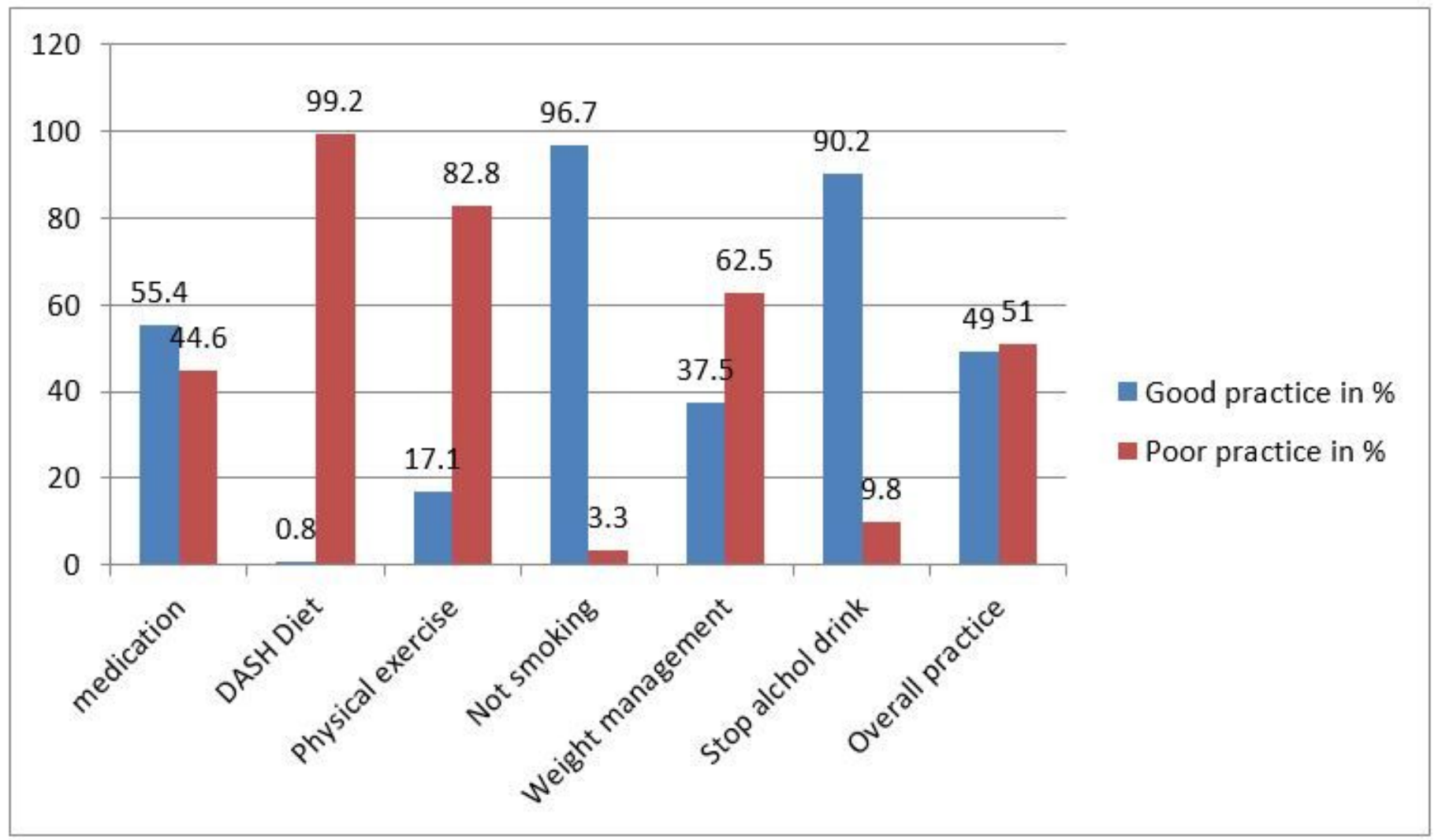

Figure 1

level of self-care practice among hypertensive patients at East Gojjam Zone, North West Ethiopia October 1-30, 2020. 